\title{
INFLUÊNCIA DE FORMAS DE ADUBAÇÃO DE SEMEADURA NA PRODUTIVIDADE DE GRÃOS DE HÍBRIDOS DE MILHO
}

\author{
GUSTAVO DE CARVALHO PERON ${ }^{1}$, RENZO GARCIA VON PINHO ${ }^{1}$, \\ LUIZ ANTONIO YANES BERNARDO JÚNIOR ${ }^{1}$, VANDER FILLIPE DE SOUZA ${ }^{1}$, \\ FRANCIELLY DE CÁSSIA PEREIRA ${ }^{1}$, INDALECIO CUNHA VIEIRA JUNIOR ${ }^{1}$, \\ MARCIO BALESTRE ${ }^{1}$ e DIMAS ANTÔNIO DEL BOSCO CARDOSO ${ }^{2}$
}

\begin{abstract}
'Universidade FederaldeLavras, Lavras-MG, Brasil-guperon@hotmail.com,renzo@dag.ufla.br,luiz_yanes@hotmail.com, vanderfsouza@gmail.com,franciellyfcp@gmail.com,indasjunior@hotmail.com,marciobalestre@des.ufla.br. ${ }^{2} \mathrm{KWS}$ - dimas.cardoso@kws.com.
\end{abstract}

Revista Brasileira de Milho e Sorgo, v.18, n.1, p. 88-98, 2019

\begin{abstract}
RESUMO - Entender como o manejo de aplicação de fertilizantes interfere no sistema produtivo é primordial para a manutenção do máximo aproveitamento da produtividade dos híbridos. Desta forma, o objetivo com este trabalho foi verificar a influência da forma de adubação de semeadura, feita a lanço ou localizada, na produtividade de grãos de 33 híbridos comerciais de milho, em quatro diferentes safras agrícolas. Foram conduzidos quatro experimentos no município de Serra do Salitre, em Minas Gerais (MG), nos meses de novembro de 2015 e de 2016, janeiro e fevereiro de 2017 e fevereiro de 2017. O delineamento experimental utilizado foi o de blocos completos casualizados com três repetições, com os tratamentos dispostos em esquema fatorial de 33 × 2, sendo 33 híbridos de milho e dois sistemas de adubação de semeadura: a lanço e localizada. Na análise conjunta da produtividade de grãos, ocorreram interações significativas entre híbridos e safras, e também entre formas de adubação e safras. Apesar da interação significativa, o sistema de adubação localizada foi superior em ambas as safras avaliadas, considerando nível de significância de 5\% pelo teste de Tukey. Mesmo com as condições climáticas menos favoráveis na segunda safra, a adubação localizada mostrou-se mais eficiente. Palavras-chave: adubação localizada, adubação a lanço, segunda safra, Zea mays L.
\end{abstract}

\section{EFFECT OF SOWING FERTILIZATION ON GRAIN PRODUCTIVITY OF MAIZE HYBRIDS}

\begin{abstract}
Understanding how the management of fertilizer application affects the production system is essential to maximize the productivity of the hybrids. The objective of this study was to verify the effect of broadcasting and banding fertilization on grain yield of 33 commercial maize hybrids in four different crop seasons. Four experiments were carried out in Serra do Salitre, state of Minas Gerais, Brazil, in November 2015, November 2016, January and February 2017. The experimental design was a randomized complete block with three replications, with treatments arranged in a $33 \times 2$ factorial scheme, 33 corn hybrids and two sowing fertilization forms, broadcast and band application. The joint analysis of grain yield showed significant interactions between hybrids and crop seasons, and also between fertilization systems and crop seasons. The unfolding of the interaction between the fertilization forms and crop seasons showed that the yield of grains in the band fertilization was superior compared to the broadcast fertilization, regardless the crop season evaluated. Even with the less favourable climatic conditions in the second harvest, the band fertilization showed to be more efficient when compared to the broadcast fertilization.
\end{abstract}

Keywords: broadcast fertilizer, band fertilizer, second crop, Zea mays L. 
O milho é uma das mais importantes commodities agrícolas, com importância tanto no setor alimentício e nutrição animal quanto na produção de biocombustíveis. No Brasil, a produtividade média nacional é de, aproximadamente, $5,4 \mathrm{mil} \mathrm{kg} \mathrm{ha}^{-1}$ (Conab, 2018). O aumento na produtividade de grãos está relacionado aos investimentos realizados na nutrição mineral e correção dos solos, que produzem resultados significativos no avanço das melhorias do sistema produtivo do milho.

Além do aumento de produtividade de grãos, diante de extensas áreas de cultivo e do curto espaço de tempo para a realização da semeadura do milho, os produtores têm buscado incorporar novas tecnologias que visem à redução de custos, com otimização de mão de obra e maior rendimento operacional. Nesse aspecto, a adubação antecipada a lanço tem sido praticada e se apresenta como uma alternativa viável, com o objetivo de melhorar o rendimento operacional e trazer economia ao produtor. A forma como o adubo é disponibilizado fisicamente para a planta, principalmente na adubação de semeadura, está diretamente relacionado com o sucesso do manejo nutricional do milho e também com a manutenção dos níveis dos próprios nutrientes no perfil do solo (Fancelli \& Dourado Neto, 2000).

Autores como Coelho et al. (2003) e Pöttker e Wiethölter (1999) descrevem que a antecipação da operação de adubação de semeadura do milho pode trazer um rendimento operacional maior, tanto na semeadura quanto na própria operação de adubação. Esse é um aspecto de grande interesse, em razão das vantagens operacionais, como maior flexibilidade no período de execução da adubação, maior rendimento operacional de máquinas, maior facilidade de distribuição a lanço, economia de tempo e de mão de obra, menor custo operacional de máquinas e redução no gasto de combustível, lubrificante e reparos.
Sousa et al. (2016) não encontrou diferenças significativas entre a adubação de semeadura a lanço feita de maneira antecipada e a adubação de semeadura feita pela semeadora quanto ao custo, tanto energético quanto econômico, independentemente do preparo de solo. Estes autores constataram, ainda, que o sistema de plantio direto, associado à adubação de semeadura feita a lanço e de forma antecipada, resultou em menor custo de operações, comparado aos sistemas de cultivo mínimo e convencional, ou a quaisquer sistemas associados à adubação de semeadura realizada no sulco pela semeadora/adubadora.

O manejo do solo pode interferir nos níveis de fósforo disponíveis ou fixados no seu perfil, em razão da sua baixa mobilidade no solo, assim como na concentração e na dispersão das raízes nos solos. Em um trabalho realizado por Nunes et al. (2011), após 14 anos de cultivo com dois métodos de adubação fosfatada, a lanço e no sulco de semeadura, e em dois diferentes sistemas de cultivo, sistema convencional com revolvimento e sistema de semeadura direta, observou-se maior concentração de fósforo nas camadas superficiais na aplicação a lanço do adubo fosfatado, principalmente no sistema de semeadura direta.

A aplicação de potássio a lanço vem ganhando destaque, principalmente em relação ao fato de que o $\mathrm{KCl}$, assim como a aplicação de nitrogênio, pode ocasionar um aumento do grau de salinidade do sulco de semeadura, sendo prejudicial às plantas. Assim, é discutida a sua utilização de forma localizada, uma vez que a salinidade auxiliada a baixos índices hídricos pode interferir negativamente no desenvolvimento inicial da cultura (Bevilaqua et al., 1996; Lana et al., 2003). Além dos problemas relacionados com a salinidade, perdas por lixiviação estão ligadas ao método de aplicação do adubo. 
Diante da forte influência da adubação nos níveis de produtividade do milho e do fato de seus custos serem cada vez mais significantes para o cultivo comercial da cultura, entender como o manejo de aplicação de fertilizantes interfere no sistema produtivo é primordial para a manutenção do máximo aproveitamento da produtividade dos híbridos. O objetivo com este trabalho foi verificar a influência da forma de adubação de semeadura, feita a lanço ou localizada, na produtividade de grãos de 33 híbridos comerciais de milho, em quatro diferentes safras agrícolas.

\section{Material e Métodos}

Foram conduzidos quatro experimentos no município de Serra do Salitre, em Minas Gerais (MG), nos meses de novembro de 2015 (safra verão 2015/16), novembro de 2016 (safra verão 2016/17), janeiro de 2017 ( $2^{\text {a }}$ safra 2017/1) e fevereiro de 2017 ( $2^{\text {a }}$ safra 2017/2). O clima local é classificado como tropical chuvoso, com temperatura média anual de $21,8^{\circ} \mathrm{C}$ e precipitação pluvial média anual de 1.372 $\mathrm{mm}$. Foram coletados os dados de temperatura média e precipitação durante o período de realização do experimento, correspondente às safras 2015/16 e 2016/17, os quais estão expostos nas Figuras 1 e 2, respectivamente.

O solo foi caracterizado como Latossolo Vermelho Amarelo distrófico, segundo o Sistema Brasileiro de Classificação de Solos (Santos, 2013). Amostras do solo foram avaliadas durante as safras, em três diferentes amostragens retiradas na profundidade de 0 a $20 \mathrm{~cm}$, apresentando granulometria médio argilosa (37,5\% de argila) e atributos químicos descritos na Tabela 1, conforme metodologia descrita por Silva (2009).

$\mathrm{O}$ delineamento experimental utilizado foi o de blocos completos casualizados com três repetições, com os tratamentos dispostos em esquema fatorial de 33 x 2, sendo 33 híbridos de milho e dois sistemas de adubação de semeadura: a lanço (LAN) e localizada (LOC). As parcelas experimentais foram constituídas por 10 linhas de 200 metros, espaçadas em $0,5 \mathrm{~m}$ entre linhas, com bordadura de quatro linhas entre as parcelas adjacentes, resultando em $1.000 \mathrm{~m}^{2}$ de área por parcela.

Em relação aos sistemas de adubação, na forma LAN, a adubação foi realizada após o preparo do solo, previamente à semeadura. $\mathrm{O}$ fertilizante foi aplicado por uma "carreta adubadora" sobre a superfície do solo de modo uniforme. Já na forma LOC, a adubação de semeadura foi realizada juntamente com a semeadura, a uma profundidade de $0,05 \mathrm{~m}$ abaixo e ao lado das sementes. Foram utilizados $500 \mathrm{~kg} \mathrm{ha}^{-1}$ do formulado NPK 09-28-17 + 0,5 Zn (MicroEssentials ${ }^{\circledR}$ S9 - Mosaic Fertilizantes). Para todos os experimentos foi adotado o sistema de cultivo convencional de preparo do solo. A adubação de cobertura foi realizada no estádio $\mathrm{V}_{4}$, com $300 \mathrm{~kg} \mathrm{ha}^{-1}$ de ureia agrícola ( $52 \%$ de $\mathrm{N})$.

Os 33 híbridos simples de milho (2B610, 2B810, 30A37, 30F35, 30F53, 30S31, AG7098, AG9030, AS1633, AS1656, AS1735, CD3612, CD3770, CD3880, DKB177, DKB290, DKB310, DKB390, IMPACTO, MG 600, P2830, P3431, P3456, P3630, P3646, P3779, P3844, P3898, RB9005, RB9077, RB9110, SUPREMO, STATUS), cedidos por empresas produtoras de sementes, foram avaliados quanto à produtividade de grãos nos dois sistemas de adubação (LAN e LOC), em média 150 dias após a semeadura.

Os dados de produtividade de grãos (kg ha-1), corrigidos para $13 \%$ de umidade, foram submetidos a análises conjuntas das quatro safras (safra verão 2015/16, safra verão 2016/17, $2^{\mathrm{a}}$ safra 2017/1, 2 ${ }^{\mathrm{a}}$ safra 2017/2). Omodelo estatístico empregado foi o seguinte: 


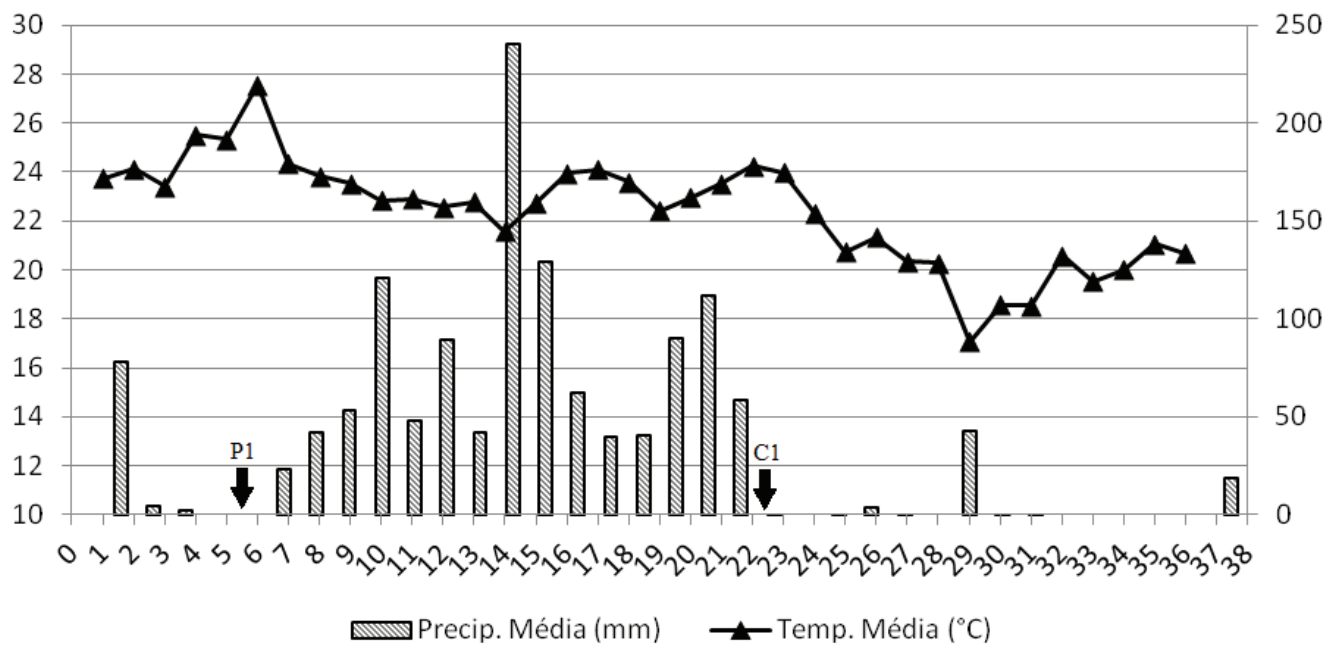

Figura 1. Dados médios de precipitação e temperatura, por decênio, na microrregião de Araxá- MG, de 31/08/2015 a 01/09/2016. Dados disponíveis no Banco de Dados Meteorológicos para Ensino e Pesquisa (BDMEP) pela estação OMM 83579. *As setas codificadas com P1 e C1 correspondem à data de semeadura do experimento safra verão 2015/16 e data de colheita do experimento safra verão 2015/16, respectivamente. Fonte: Dados da Rede INMET (2017).

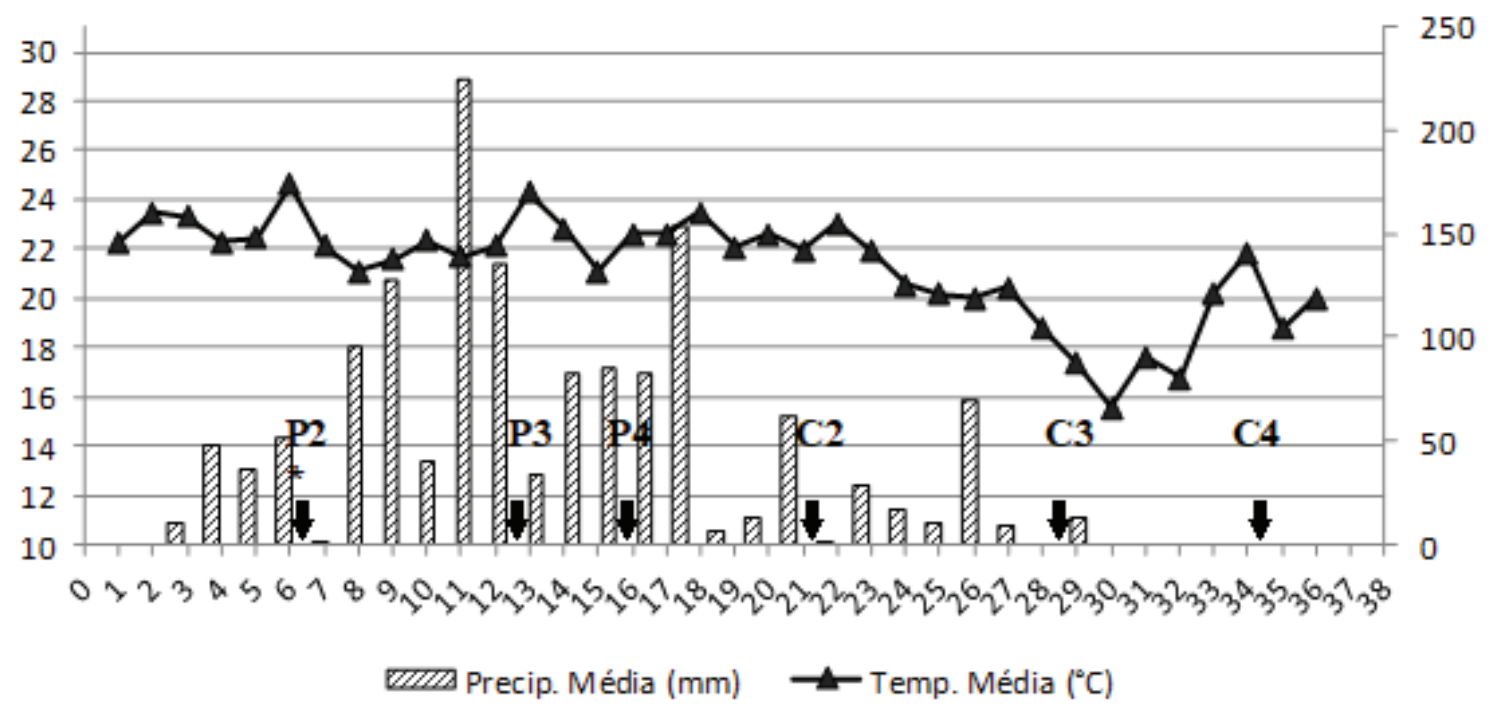

Figura 2. Dados médios de precipitação e temperatura por decênio, na microrregião de Araxá-MG, de 31/08/2016 a 01/09/2017. Dados disponíveis no Banco de Dados Meteorológicos para Ensino e Pesquisa (BDMEP) pela estação OMM 83579. *As setas codificadas com P2, P3 e P4 correspondem à data de semeadura dos experimentos safra verão 2016/17, $2^{\text {a }}$ safra 2017/1 e 2 2017/2, respectivamente. As setas codificadas com C2, C3 e C4, correspondem à data de colheita dos experimentos safra verão 2016/17, $2^{\mathrm{a}}$ safra 2017/1 e 2a 2017/2, respectivamente. Fonte: Dados da Rede INMET (2017). 
Tabela 1. Resultados das análises de fertilidade $(00-20 \mathrm{~cm})$ de um Latossolo Vermelho Amarelo distrófico coletado na área de condução do experimento anteriormente à semeadura dos experimentos, no período de 30/08/2015 a 30/01/2017.

\begin{tabular}{ccccccccccc}
\hline \multirow{2}{*}{ Safras } & $\mathbf{p H}$ & $\mathbf{P} *$ & $\mathbf{K}$ & $\mathbf{C a}$ & $\mathbf{M g}$ & $\mathbf{V}$ & $\mathbf{m}$ & $\mathbf{t}$ & $\mathbf{T}$ & M.O. \\
\cline { 2 - 11 } & $\mathrm{H}_{2} \mathrm{O}$ & \multicolumn{2}{c}{$-\mathrm{mg} \mathrm{dm}^{-3}-$} & \multicolumn{2}{c}{$\mathrm{cmolc} \mathrm{dm}^{-3}-$} & $(\%)$ & & $-\mathrm{cmolc} \mathrm{dm}^{-3}-$ & $\mathrm{g} \mathrm{kg}^{-1}$ \\
Verão 2015/16 & 5,6 & 27,1 & 0,4 & 2,0 & 0,9 & 53,0 & 1,0 & 3,55 & 6,55 & 34 \\
Verão 2016/17 & 5,8 & 25,4 & 0,5 & 2,1 & 1,0 & 54,3 & 0,3 & 4,50 & 8,91 & 29 \\
$\mathbf{2}^{\mathbf{a}}$ Safra 2017/1 & 5,6 & 27,6 & 0,3 & 2,1 & 0,4 & 42,8 & 0,0 & 2,77 & 6,47 & 39 \\
$\mathbf{2}^{\mathbf{a}}$ Safra 2017/2 & 5,9 & 24,2 & 0,4 & 4,4 & 1,1 & 65,4 & 0,0 & 5,85 & 8,95 & 37 \\
\hline
\end{tabular}

V: saturação por bases; m: saturação por alumínio; t: capacidade de troca catiônica (CTC) efetiva; T: CTC a pH 7,0; M.O.: matéria orgânica. $* \mathrm{P}\left(\mathrm{mg} \mathrm{dm}^{-3}\right)$ resina

$Y_{i j k l}=\mu+H_{i}+T_{j}+S_{l}+B(S)_{k l}+H T_{i j}+H S_{i l}+T S_{j l}$ $+H T S_{i j l}+e_{i j k l}$

em que: $Y_{i j k}$ : Valor observado do híbrido $i$, da forma de adubação de semeadura $j$, e do bloco $k$ dentro de safra $l ; \mu$ : media geral; $H_{i}$ : efeito aleatório de híbrido, para $i=1,2, \ldots, 33 ; T_{j}$ : efeito fixo da forma de adubação de semeadura, para $j=1,2 ; S_{l}$ : efeito fixo da safra, para $l=1$ (safra verão 2015/16), 2 (safra verão 2016/17), 3 (2 $2^{\text {a }}$ safra 2017/1) ou 4 ( $2^{\mathrm{a}}$ safra 2017/2); $B(S)_{l k}$ : efeito do bloco $k$ dentro de safra $l$, para $k=1,2,3$ e $l=1,2,3$ ou 4; $H T_{i j}$ : efeito da interação entre híbrido $i$ com a forma de adubação de semeadura $j ; H S_{i l}$ : efeito da interação entre híbrido $i$ com a safra $l ; T S_{j l}$ : efeito da interação entre forma de adubação de semeadura $j$ com a safra $l ; H T S_{i j l}$ : efeito da interação entre híbrido $i$, com a forma de adubação de semeadura $j$ e com a safra $l$; $e$ : efeito do erro experimental da observação referente ao efeito aleatório do híbrido $i$, do efeito fixo da forma de adubação de semeadura $j$, do efeito fixo da safra $l$ e do bloco $k$ dentro da safra $l$.

Após verificar a significância dos efeitos na análise de variância, os dados médios de produtividade de grãos foram submetidos ao teste de comparação de média pelo teste de Tukey, a 5\% de probabilidade. Nas análises conjuntas, os dados de produtividade de grãos foram obtidos por meio do procedimento de estimação/predição REML/BLUP (máxima verossimilhança restrita/melhor predição linear não viciada) (Patterson \& Thompson, 1971). Todas as análises estatísticas foram realizadas utilizando-se o programa SAS ${ }^{\circledR}($ SAS Institute, 1996).

\section{Resultados e Discussão}

A análise conjunta da produtividade de grãos considerando todas as safras avaliadas mostrou diferença significativa em relação aos efeitos de híbridos, formas de adubação e safras. Houve interação significativa entre híbridos e safras, e também entre formas de adubação e safras. A interação entre híbridos e formas de adubação e a interação tripla entre híbridos, formas de adubação e safras não foram significativas (Tabela 2).

O efeito significativo de híbridos pode ser entendido pelo desempenho per se de todos os híbridos avaliados. A predição dos BLUPs do efeito genético aleatório de híbridos para produtividade de grãos 
Tabela 2. Quadro da análise conjunta de todos os experimentos (safra verão 2015/16, safra verão 2016/17,

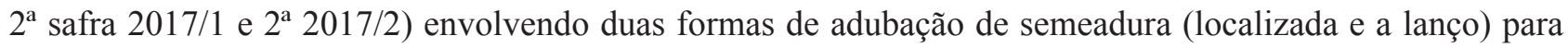
produtividade de grãos de híbridos de milho, em Serra do Salitre- MG, 2017.

\begin{tabular}{|c|c|c|c|}
\hline Variância aleatória & Componente da variância $(\mathrm{CpV})$ & Valor $\mathbf{Z}$ & $P$ valor $Z$ \\
\hline Híbridos (H) & 135120 & 7422,10 & $0,0339 *$ \\
\hline H x Adubação (A) & 71501 & 7417,70 & $0,7518^{\mathrm{NS}}$ \\
\hline$H \times$ Safras (S) & 137138 & 7427,30 & $0,0018^{*}$ \\
\hline$H \times A \times S$ & 107530 & 7420,70 & $0,0783^{\mathrm{NS}}$ \\
\hline Variância fixa & Graus de liberdade & Valor $\mathbf{F}$ & $\mathbf{P}$ valor $\mathbf{F}$ \\
\hline A & 1 & 126,73 & $0,0001^{*}$ \\
\hline $\mathbf{S}$ & 3 & 11,39 & $0,0001 *$ \\
\hline A $\times S$ & 3 & 124,99 & $0,0001 *$ \\
\hline Bloco/Safra & 8 & 24,40 & $0,0001 *$ \\
\hline Resíduo & 996947 & & \\
\hline Total & 449 & $\mathrm{CV}=10$ & \\
\hline
\end{tabular}

Os valores seguidos de * apresentaram diferença estatística significativa no teste de verossimilhança (teste Z) ou no teste F, a $5 \%$ de significância. Os valores seguidos de ${ }^{\mathrm{NS}}$ não apresentaram diferença estatística significativa em relação ao mesmo nível de significância dos testes.

mostrou que os híbridos que mais se destacaram nos quatro experimentos foram 2B810 PW, AS1633 PRO3, DKB310 PRO3 e P3898 Convencional, com a estimativa de produtividade próxima dos 11.000 $\mathrm{kg} \mathrm{ha}^{-1}$. O híbrido RB9005 PRO2 teve desempenho abaixo dos demais, ficando com uma estimativa de produtividade próxima de $8.000 \mathrm{~kg} \mathrm{ha}^{-1}$.

Este resultado foi semelhante ao obtido por Bertolini et al. (2008), em um trabalho de antecipação da adubação de semeadura do milho, aplicada de duas formas, a lanço ou localizada no sulco de semeadura, encontrando significância estatística para o efeito de híbridos. Porém, os autores relataram que este efeito se deve apenas às divergências genotípicas entre os híbridos do seu trabalho, com uso de híbridos simples, duplos e triplos. O mesmo autor também relatou não haver diferença estatística significativa para a interação entre híbridos e a aplicação da adubação de semeadura.

O resultado também concorda com o obtido no trabalho de Model e Anghinoni (1992), no qual não houve efeito significativo para a produtividade de grãos entre cultivares de milho e diferentes modos de aplicação de adubos fosfatados e tipos de preparo de solo. Pavinato e Ceretta (2004) também obtiveram resultados semelhantes em um Latossolo Vermelho distroférrico típico da região de Coronel Bicaco-RS, com teores de fósforo muito altos, até $20 \mathrm{~cm}$ de profundidade. Os autores relataram que os altos teores de fósforo, aliados à adequada distribuição de chuvas durante o ciclo do milho, favoreceu o processo de difusão deste nutriente no solo, o que contribuiu para a obtenção dos resultados encontrados. 
A interação significativa entre híbridos e safras em relação à produtividade de grãos demonstra um comportamento diferente no desempenho dos híbridos em relação às épocas de semeadura. Entretanto, a antecipação da semeadura da $2^{\mathrm{a}}$ safra, como no caso do experimento de 2017/1, pode ter proporcionado melhores condições climáticas para o desenvolvimento e a produtividade de grãos de milho, como também é relatado nos trabalhos de Aguiar et al. (2008), Duarte e Paterniani (1999) e Tsunechiro et al. (2006).

$\mathrm{O}$ desdobramento da interação entre as formas de adubação de semeadura e as safras evidenciou que a produtividade de grãos na adubação localizada foi superior à adubação a lanço independentemente das safras avaliadas. No entanto, a produtividade de grãos variou entre as safras para cada forma de adubação de semeadura, sem apresentar interação complexa (Figura 3). O experimento da safra verão 2015/16 foi o mais produtivo para a adubação localizada, com $14.731 \mathrm{~kg} \mathrm{ha}^{-1}$ de grãos, e a $2^{\mathrm{a}}$ safra $2017 / 2$ foi o pior desempenho produtivo para ambas as formas de adubação (Tabela 3).

Portanto, mesmo com as condições climáticas menos favoráveis na segunda safra, a adubação localizada mostrou-se mais eficiente, quando comparada à adubação de semeadura feita a lanço. Era esperado o maior efeito da aplicação de fósforo de forma localizada em relação à aplicação a lanço na segunda safra. Isso porque o fósforo é transportado da solução do solo para as raízes por difusão, que é altamente dependente da umidade do solo. Quando a adubação de semeadura é realizada a lanço em épocas nas quais a presença de "veranicos" (períodos de baixíssima ou nenhuma precipitação) é mais frequente, como ocorre na segunda safra, o processo de difusão é dificultado em função da menor umidade nas camadas mais superficiais do solo. Entretanto, as diferenças entre os sistemas de adubação são mais evidentes em condições ambientais mais favoráveis, como aconteceu na safra verão 2015/16.

O efeito de safra na interação entre as formas de adubação e as safras pode ser associado às diferenças climáticas entre os anos, principalmente aos efeitos que a maior ou menor pluviosidade nos experimentos proporcionam, em relação à forma de adubação de semeadura. Com maiores índices de pluviosidade e, consequentemente, maior umidade do solo, pode ocorrer tanto um aumento na absorção de nutrientes quanto uma maior perda de nutrientes por lixiviação, principalmente de nitrogênio e potássio, por causa das diferenças entre as formas como a adubação de semeadura é realizada (Rosolem et al., 2006).

Barreto e Fernandes (2002), no Tabuleiro Costeiro de Sergipe, em um Argissolo Amarelo com teor inicial de $1 \mathrm{mg} \mathrm{dm}^{-3}$ de fósforo $\left(\mathrm{Mehlich}^{-1}\right.$ ) na camada de $0-20 \mathrm{~cm}$ e alto teores de areia, comparados com a maioria dos solos de cerrado, encontraram maiores produtividades de milho com aplicação do fósforo a lanço em comparação com a aplicação no sulco (4.260 kg ha ${ }^{-1}$ de milho com a adubação de semeadura a lanço e de $3.620 \mathrm{~kg} \mathrm{ha}^{-1}$ com a adubação no sulco). É importante relatar que o solo utilizado nesse trabalho apresentava baixos teores de argila e óxidos de ferro e de alumínio no horizonte A. Além disso, as produtividades obtidas no trabalho podem ser consideradas baixas.

Já Barbosa et al. (2015), em trabalho realizado com condições climáticas semelhantes às do presente trabalho (tropical chuvoso, com chuvas distribuídas de outubro a março), com o cultivo do milho segunda safra e sua resposta a formas de adubação fosfatada de semeadura, a lanço e localizado no sulco, relataram não haver diferença estatística significativa entre os métodos de adubação para produtividade de grãos de milho. 


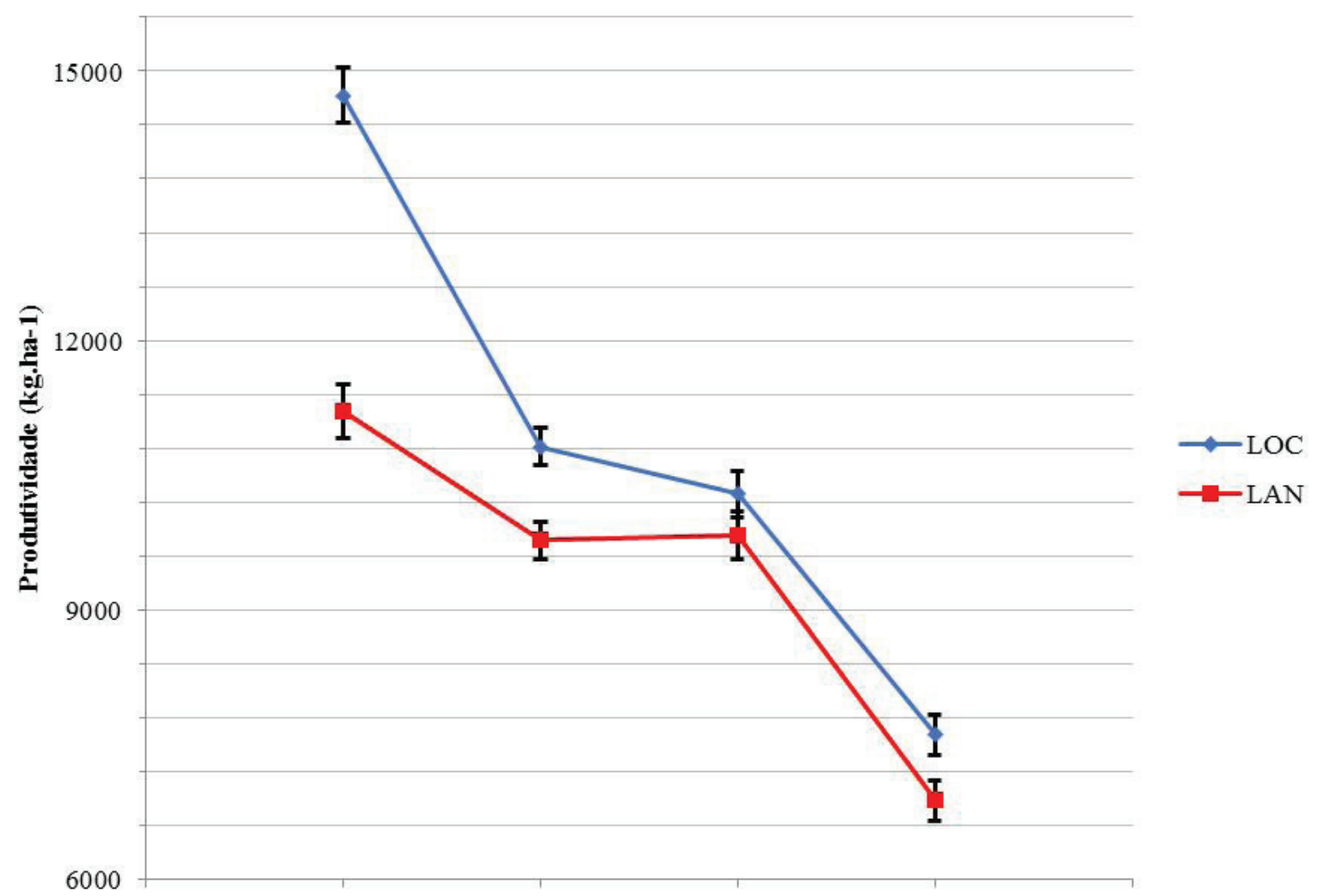

Safra verão 2015/16 Safra verão 2016/17 $2^{a}$ safra 2017/1 $2^{a}$ safra 2017/2

Figura 3. Comportamento da média de produtividade de grãos de milho e desvio padrão das formas de adubação de semeadura, realizadas de maneira localizada no sulco (LOC) e a lanço (LAN), ao longo dos quatro experimentos, realizados em Serra do Salitre-MG, de 2015 a 2017.

Tabela 3. Comparação das médias de produtividade de grãos de milho $\left(\mathrm{kg} \mathrm{ha}^{-1}\right)$ do desdobramento da interação entre duas formas de adubação de semeadura, localizada (LOC) e a lanço (LAN), em relação a quatro experimentos realizados nas safras de verão e 2a safra, em Serra do Salitre-MG, de 2015 a 2017.

\begin{tabular}{llll}
\hline Experimento & LOC & LAN & Médias \\
\hline Safra verão 2015/16 & $14.731 \mathrm{Aa}$ & $11.209 \mathrm{Ab}$ & $12.970 \mathrm{~A}$ \\
Safra verão 2016/17 & $10.814 \mathrm{Ba}$ & $9.771 \mathrm{Ab}$ & $10.293 \mathrm{~B}$ \\
$2^{\mathrm{a}}$ safra 2017/1 & $10.289 \mathrm{Ba}$ & $9.827 \mathrm{Ab}$ & $10.058 \mathrm{~B}$ \\
$2^{\mathrm{a}}$ safra 2017/2 & $7.607 \mathrm{Ca}$ & $6.876 \mathrm{Bb}$ & $7.242 \mathrm{C}$ \\
\hline Médias & $10.860 \mathrm{a}$ & $9.421 \mathrm{~b}$ &
\end{tabular}

Médias seguidas pelas mesmas letras (minúscula) nas linhas e (maiúsculas) nas colunas não diferem entre si, pelo teste Tukey, a 5\% de probabilidade. 
Resultados obtidos por Anghinoni e Barber (1980) e Klepker e Anghinoni (1993) concordam com os deste trabalho. Estes relataram um aumento da absorção de fósforo pelas plantas de milho, em consequência da utilização da aplicação do adubo fosfatado no sulco de semeadura, incorporado com um volume maior de solo. Com o fósforo localizado, houve relatos de um maior comprimento de raízes das plantas de milho que, em contato com o adubo fosfatado, apresentaram melhores médias de produtividade de grãos. Prado et al. (2001) realizaram um trabalho em Uberaba-MG, utilizando um Latossolo Vermelho-Escuro distrófico com $66 \%$ de argila e $5 \mathrm{mg} \mathrm{dm}^{-3}$ de $\mathrm{P}\left(\mathrm{em} \mathrm{Mehlich}^{-1}\right.$ ), na camada 0-20 cm, e obtiveram maiores produtividades de grãos de milho quando o adubo fosfatado foi aplicado de forma localizada, em relação à aplicação a lanço.

A maioria dos trabalhos nos quais se comparou a produtividade de grãos de diversas culturas em relação ao método de adubação de semeadura demonstrou não haver diferença significativa entre as médias de produtividade de grãos entre os tratamentos avaliados (Barbosa et al., 2015; Bertolini et al., 2008; Bertolini \& Gamero, 2010; Biesdorf et al., 2016; Lana et al., 2003; Nunes et al., 2011). Estes trabalhos têm em comum as características de solo com fertilidade construída, índices do nutriente fósforo considerados de médios a altos e a inexistência de restrições hídricas durante a condução deles.

\section{Conclusões}

A interação entre híbridos e as formas de adubação de semeadura não foi significativa, demonstrando que o desempenho produtivo dos híbridos avaliados foi semelhante quanto à produtividade de grãos, independentemente da forma como a adubação de semeadura foi realizada.

A adubação de semeadura feita de forma localizada no sulco de semeadura proporcionou maior produtividade de grãos do que a adubação de semeadura feita a lanço, independentemente da época de semeadura e da safra.

\section{Agradecimentos}

À Fundação de Amparo à Pesquisa do Estado de Minas Gerais (Fapemig), pelo suporte financeiro, e à empresa KWS, pelo apoio no desenvolvimento do projeto.

\section{Referências}

AGUIAR, R. A. de; SILVEIRA, P. M. da; MOREIRA, J. A. A.; WANDER, A. E. Análise econômica de diferentes práticas culturais na cultura do milho (Zea mays L.). Pesquisa Agropecuária Tropical, Goiânia, v. 38, n. 4, p. 241-248, out./dez. 2008.

ANGHINONI, I.; BARBER, S. A. Phosphorus application rate and distribution in the soil and phosphorus uptake by corn. Soil Science Society of America Journal, Madison, v. 44, n. 5, p. 1041-1044, 1980.

DOI: $10.2136 /$ sssaj1980.03615995004400050034x.

BARBOSA, N. C.; ARRUDA, E. M.; BROD, E.; PEREIRA, H. S. Distribuição vertical do fósforo no solo em função dos modos de aplicação. Bioscience Journal, Uberlândia, v. 31, n. 1, p. 87-95, 2015.

DOI: 10.14393/BJ-v31n1a2015-18196.

BARRETO, A. C.; FERNANDES, M. F. Produtividade e absorção de fósforo por plantas de milho em função de doses e modos de aplicação de adubo fosfatado em solo de tabuleiro costeiro. Revista Brasileira de Ciência do Solo, Viçosa, MG, v. 26, n. 1, p. 151-156, 2002.

DOI: $10.1590 / \mathrm{S} 0100-06832002000100015$. 
BERTOLINI, E. V.; GAMERO, C. A.; SALATA, A. da C.; PIFFER, C. R. Antecipação da adubação de semeadura do milho em dois sistemas de manejo do solo. Revista Brasileira de Ciência do Solo, Viçosa, MG, v. 32, n. 6, p. 2355-2366, dez. 2008.

DOI: $10.1590 / \mathrm{S} 0100-06832008000600014$.

BERTOLINI, E. V.; GAMERO, C. A. Demanda energética e produtividade da cultura do milho com adubação de pré-semeadura em dois sistemas de manejo do solo. Revista Energia na Agricultura, Botucatu, v. 25, p. 1-23, 2010.

DOI: 10.17224/EnergAgric.2010v25n3p01-23.

BEVILAQUA, G. A. P.; BROCH, D. L.; POSSENTI, J. C.; VILlELA, F. A. Posição do fósforo e potássio na adubação da semente e no crescimento de plântulas de milho. Revista Brasileira de Agrociência, Pelotas, v. 2, n. 2, p. 87-92, 1996.

BIESDORF, E. M.; BIESDORF, E. M.; TEIXEIRA, M. F. F.; DIETRICH, O. H.; PIMENTEL, L. D.; ARAÚJO, C. de. Métodos de aplicação de nitrogênio na cultura do milho em solo de cerrado. Revista de Agricultura Neotropical, Cassilândia, v. 3, n. 1, p. 44-50, 2016.

DOI: $10.32404 /$ rean.v3i1.805.

COELHO, A. M.; CRUZ, J. C.; PEREIRA FILHO, I. A. Rendimento do milho no Brasil: chegamos ao máximo? Piracicaba: POTAFOS, 2003. 12 p. Encarte do Informações Agronômicas, n. 101, mar. 2003.

CONAB. Companhia Nacional de Abastecimento. Série histórica das safras. Disponível em: <https:// www.conab.gov.br/info-agro/safras/serie-historica-dassafras?start=20>. Acesso em: 23 maio 2018.

COSTA, N. R.; ANDREOTTI, M.; GAMEIRO, R. de A.; PARIZ, C. M.; BUZETT, S.; LOPES, K. S. M. Adubação nitrogenada no consórcio de milho com duas espécies de braquiária em sistema plantio direto. Pesquisa Agropecuária Brasileira, Brasília, DF, v. 47, n. 8, p. 1038-1047, ago. 2012. p. 1038-1047.

DOI: $10.1590 / \mathrm{S} 0100-204 \mathrm{X} 2012000800003$.
DUARTE, A. P.; PATERNIANI, M. E. A. G. Z. (Coord.). Cultivares de milho no Estado de São Paulo: resultados das avaliações regionais IAC/CATI/Empresas-1998/99. Campinas: Instituto Agronômico, 1999.

FANCELLI, A. L.; DOURADO NETO, D. Produção de milho. Guaíba: Agropecuária, 2000. 360 p.

INMET. Instituto Nacional de Meteorologia. Brasília, DF, 2017. Disponível em: <http://www.inmet.gov.br/ portal/>. Acesso em: 13 jun. 2017.

KLEPKER, D.; ANGHINONI, I. Phosphate uptake and corn root distribution as affected by fertilizer placement and soil tillage. Agronomy Trends in Agriculture Science, San Diego, v. 1, p. 111-115, 1993.

LANA, R. M. Q; VILELA FILHO, C. E.; ZANÃO JÚNIOR, L. A.; PEREIRA, H. S.; LANA, A. M. Q. Adubação superficial com fósforo e potássio para soja. Scientia Agrária, Piracicaba, v. 4, n. 1/2, p. 53-60, 2003. DOI: $10.5380 /$ rsa.v4i1.1066.

MODEL, N. S.; ANGHINONI, I. Respostas do milho a modos e técnicas de preparo do solo. Revista Brasileira de Ciência do Solo, Viçosa, MG, v. 16, p. 55-59, 1992.

NUNES, R. de S.; SOUSA, D. M. G. de; GOEDERT, W. J.; VIVALDI, L. J. Distribuição de fósforo no solo em razão do sistema de cultivo e manejo da adubação fosfatada. Revista Brasileira de Ciência do Solo, Viçosa, MG, v. 35, n. 3, p. 877-888, 2011.

DOI: $10.1590 / \mathrm{S} 0100-06832011000300022$.

PATTERSON, H. D.; THOMPSON, R. Recovery of inter-block information when block sizes are unequal. Biometrika, v. 58, n. 3, p. 545-554, 1971.

DOI: $10.2307 / 2334389$.

PAVINATO, P. S.; CERETTA, C. A. Fósforo e potássio na sucessão trigo/milho: épocas e formas de aplicação. Ciências Rural, Santa Maria, v. 34, n. 6, p. 1779-1784, nov./dez. 2004.

DOI: $10.1590 / \mathrm{S} 0103-84782004000600017$. 
PÖTTKER, D.; WIETHÖLTER, S. Antecipação da aplicação de nitrogênio em milho. Passo Fundo: Embrapa Trigo, 1999. 3 p. (Embrapa Trigo. Pesquisa em Andamento Online, 1). Disponível em: <http://www.cnpt.embrapa.br/ biblio/p_pa01.htm>. Acesso em: 1 fev. 2016.

PRADO, R. M.; FERNANDES, F. M.; ROQUE, C. G. Resposta da cultura do milho a modos de aplicação e doses de fósforo, em adubação de manutenção. Revista Brasileira de Ciência do Solo, Viçosa, MG, v. 25, n. 1, p. 83-90, 2001. DOI: 10.1590/S0100-06832001000100009.

RESENDE, A. V. de; COELHO, A. M.; SANTOS, F. C. dos; LACERDA, J. J. de J. Fertilidade do solo e manejo da adubação NPK para alta produtividade de milho no Brasil Central. Sete Lagoas: Embrapa Milho e Sorgo, 2012. 12 p. (Embrapa Milho e Sorgo. Circular Técnica, 181).

ROSOLEM, C. A.; SANTOS, F. P. dos; FOLONI, J. S. S.; CALONEGO, J. C. Potássio no solo em conseqüência da adubação sobre a palha de milheto e chuva simulada. Pesquisa Agropecuária Brasileira, Brasília, DF, v. 41, n. 6, p. 1033-1040, jun. 2006.

DOI: 10.1590/S0100-204X2006000600020.
SANTOS, H. G. dos; JACOMINE, P. K. T.; ANJOS, L. H. C. dos; OLIVEIRA, V. A. de; LUMBRERAS, J. F.; COELHO, M. R.; ALMEIDA, J. A. de; CUNHA, T. J. F.; OLIVEIRA, J. B. de. Sistema brasileiro de classificação de solos. 3. ed. rev. e ampl. Brasília, DF: Embrapa, 2013. 353 p.

SILVA, F. C. da (Ed.). Manual de análises químicas de solos, plantas e fertilizantes. 2. ed. Brasília, DF: Embrapa Informação Tecnológica; Rio de Janeiro: Embrapa Solos, $2009.627 \mathrm{p}$

SOUSA, D. M. G. de; REIN, T. A.; SANTOS JÚNIOR, J. de D. G. dos. Manejo da adubação fosfatada para culturas anuais no cerrado. Planaltina, DF: Embrapa Cerrados, 2016. 10 p. (Embrapa Cerrados. Circular Técnica, 33).

SAS INSTITUTE. Advanced general linear models with na emphasis on mixed models. Cary, 1996. 614 p.

TSUNECHIRO, A.; OLIVEIRA, M. D. M.; FURLANETO, F. P. D.; DUARTE, A. P. Análise técnica e econômica de sistemas de produção de milho safrinha, região do Médio Paranapanema, Estado de São Paulo. 2006. Disponível em: <http://www.infobibos.com/Artigos/2006_3/Safrinha/ index.htm>. Acesso em: 5 jan. 2017. 